\title{
Pulkovo Observatory's Status in 19th Century Positional Astronomy
}

\author{
Kevin Krisciunas \\ Joint Astronomy Centre \\ 665 Komohana Street \\ Hilo, Hawaii 96720 USA
}

\begin{abstract}
The most significant basis of the reputation of a scientific organization is the accuracy and influence of its work. From a comparison of values of certain astronomical constants and stellar parallaxes obtained at Pulkovo and elsewhere, the extremely high weight given to the Pulkovo values (e.g. by Newcomb) is further justified in retrospect given the small deviations between Pulkovo values and the "modern" values accepted a century later.
\end{abstract}

\section{Introduction}

Most observatories, among them Greenwich and Harvard, the U. S. Naval Observatory, and even Mauna Kea, had very uncertain and modest beginnings. Occasionally, however, it was planned to establish an observatory which would have, from the very start, a number of world class instruments. For a few this aim was, to a large extent, achieved. Tycho Brahe's island observatory was one such institution, where upwards of 17 instruments were built and used (Krisciunas 1988, pp. 49 and 53).

Another institution that can be included in this category is Pulkovo Observatory, whose 150th birthday we celebrate this year. The first and foremost purpose of the observatory was "to provide uninterrupted observations as accurate as possible which serve the progress of astronomy." With the means provided for its construction $(600,000$ silver rubles $=2,100,000$ assignat [paper] rubles $)$, it was clearly intended that Pulkovo be a major scientific institution. Given that positional astronomy was so highly regarded in the 19th century, it is no wonder that a number of telescopes were ordered: an Ertel transit instrument (for the determination of absolute right ascensions), an Ertel vertical circle (for the determination of absolute declinations), a Repsold meridian circle (for the determination of differential stellar coordinates) and prime vertical transit (for the determination of aberration and nutation), a Merz \& Mahler heliometer, and the 15-inch Merz \& Mahler refractor, then the largest in the world, to be used for the discovery and measurement of double stars (Krisciunas 1988 , chapter 5 , and references therein). 


\section{Expectations}

W. Struve's elaborate 1845 Description de L'Observatoire Astronomique central de Poulkova gives a breakdown of the 2.1 million rubles allocated for the establishment of the observatory, including 40,000 for the relocation of the 2000 inhabitants of the village, $1,700,000$ for construction (including the piers for the instruments), 299,000 for the instruments, 28,000 for the library, and 17,500 for the publication of the Description itself (F. G. W. Struve 1845, p. 53). According to Otto Wilhelm Struve, his father was given carte blanche by the Tsar to order the "most perfect instruments the technology of the time could provide" (Otto Struve 1895, p. 49, translation Batten).

Of course it is one thing to spend a lot of money, and another to achieve great science. Already in the fall of $1838 \mathrm{~W}$. Struve had a feeling for how good the instruments were to be. He journeyed to Hamburg to visit the Repsolds and to Munich to visit the firms of Ertel and Merz \& Mahler. He reports that he looked at celestial and terrestrial targets with the 15-inch objective, remarking on the excellent achromatic image of $\alpha$ Aquilae. He observed an artificial double star situated 2700 feet away at the Church of St. Petri. The two components of this artificial double consisted of two "stars" 0.24 and 0.42 arcsec in diameter, separated by 1.24 arcsec, which he observed easily with a magnification of 1600 . Clearly, the optical characteristics of the great refractor were excellent (W. Struve 1839).

One of the fundamental means of operation that was to be put into practice at Pulkovo Observatory we may label "Struve's method", which can be considered a carryover from W. Struve's Dorpat years. It amounts to an attempt to eliminate systematic and random errors by relying to the maximum degree on the data of one's own observatory.

\section{The State of the Art}

What kind of progress was being made in positional astronomy prior to 1800 ? In Fig. 1 we show the improvement in accuracy of determining the coordinates of a star. By 1700 a resolution of 15 arcsec was achieved, 8 arcsec by 1725 , and 0.5 arcsec by 1800 (Chapman 1983, Hughes 1984).

As always, actual probable errors are larger than the instrumental resolution. In the Positiones Mediae (Struve 1852, pp. 48-50), based on observations at Dorpat, for 109 primary stars we find median probable errors of \pm 0.022 seconds of time in right ascension and \pm 0 " 19 in declination. This can be compared to the modern Carlsberg meridian observations (L. Morrison 1989, elsewhere in this volume), which are good to $\pm 0 \prime$.12 (mean error). 


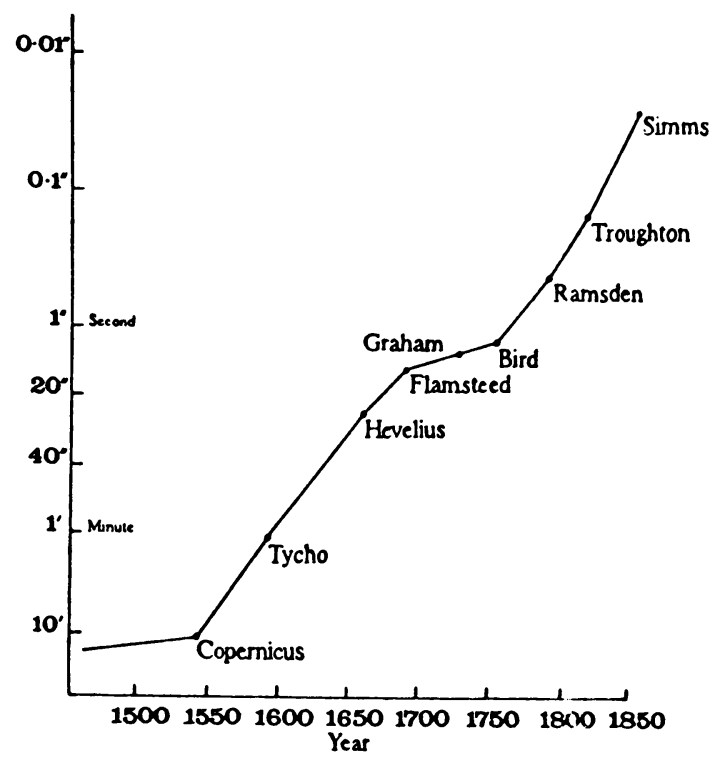

Fig. 1 - The resolution of graduated scales (from Chapman 1983).

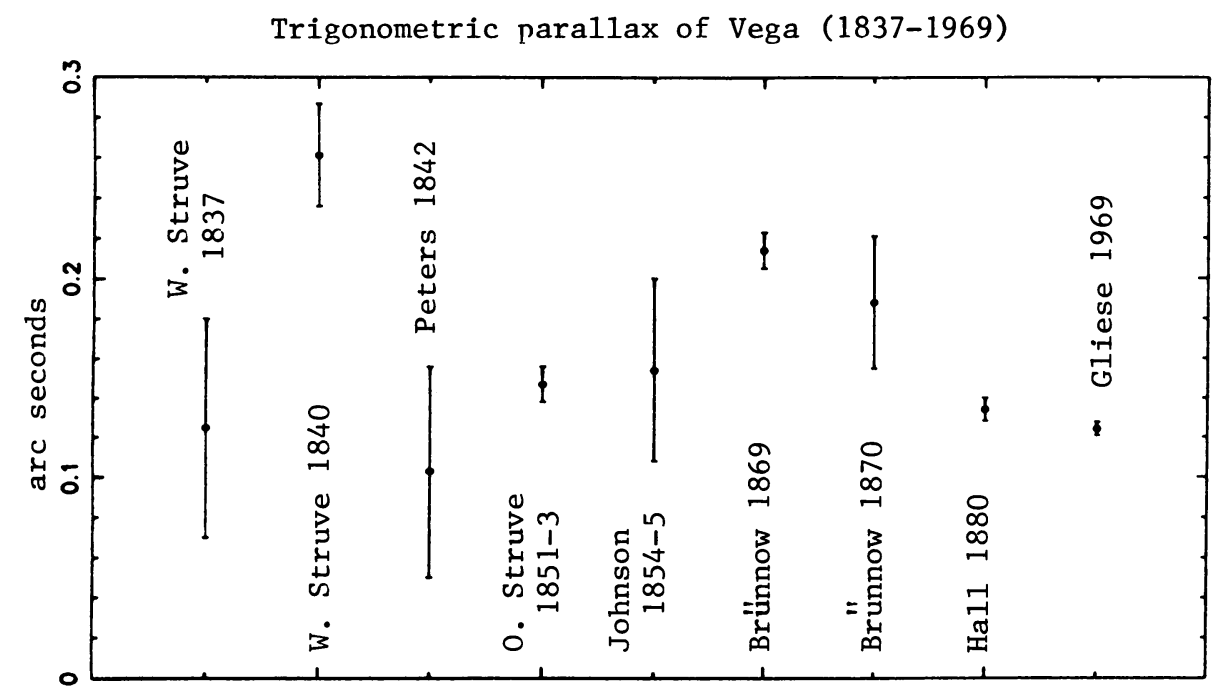

Fig. 2 - Various values of the measured parallax of $\alpha$ Lyrae (Vega), taken from Hall (1888, p. 12), but also including W. Struve's preliminary value (1837) and the modern value from Gliese (1969). Error bars are probable errors. 
Repeated measurements of the same star yield smaller internal errors. As an example consider measurements of the parallax of Vega (Fig. 2). Wilhelm Struve's preliminary 1837 value of $0.125 \pm 0$ " 055 , based on 17 micrometrical measures with the Dorpat 9.6-inch refractor (see Batten 1988, p. 121) was later revised to $0 ! 261 \pm 0$ " 025 (W. Struve 1840) based on a total of 96 measures. Other values obtained throughout the 19th century show some scatter, but most of the values are within one standard deviation of the modern value $\left(0^{\prime \prime} \cdot 124 \pm 0\right.$ 0.005, Gliese 1969).

\section{Astronomical Constants}

If the underlying goal of Pulkovo Observatory was the production of the most accurate star catalogues, this involved not only well built and carefully operated instruments, but also the use of the best reduction parameters. This required a theory of errors, such as that elaborated by Gauss, Bessel, and W. Struve, and an analysis of the cause and remedy of systematic and random errors. More specifically for astronomy it involved the derivation of accurate values for precession, nutation, and aberration.

The concept of fundamental constants has undergone some major changes since the foundation of Pulkovo Observatory. The solar parallax (or distance to the Sun) was once a primary constant, but now is a derived constant. The same is true of the constant of nutation. And the constant of precession is not really a constant at all, but a dynamical theory of the rotation of the Earth. As de Sitter (1938, p. 213) points out: "It is of much greater importance that the value of a fundamental constant used in any individual investigation should be exactly defined than that it should be the best available at the moment."

This is getting ahead of the story, however, because in the first half of the 19th century there was no theory of astronomical constants. There was only a relatively small number of astronomers who sought to derive the best values from the raw data, and these data would lead later to the work on the theory of constants.

In the case of precession the reader is referred to Dreyer (1882), Newcomb (1898), and Lieske (1985). From Newcomb (1898, p. 10) we show in Fig. 3 values of the "general precession in longitude" reduced to the year 1850 (with apparently the terms in time squared and time cubed included). I cannot add to what Lieske (1985) has said, but it is obvious that Bessel's first value and Nyrén's value stick out as different. In the case of Nyrén his result was obtained from a faulty determination of the equinox of 1865 (Dreyer 1918, on p. 348). Values obtained by Otto Wilhelm Struve and C. A. F. Peters are consistent with the values adopted by Dreyer and Newcomb. Yet, Newcomb (1895, pp. 125-6) states: 
The [value of precession] which seems entitled to most weight is that of Ludwig Struve ... This work was suggested by the completion of Auwers' re-reduction of Bradley's Observations, and of the Pulkowa standard catalogues for 1845,1855 , and 1865 . It depends entirely on the Bradley stars, and the result, when reduced to the most probable equinox, may be regarded as the best now derivable from those stars, or, at least, as not susceptible of any large correction.

It was Newcomb's value published in 1898 (known as N96, however) that was adopted for The Nautical Almanac and in The American Ephemeris in 1901 and also by the IAU in 1964 (5025.64 arcsec per tropical century for the year 1900; see Explanatory Supplement 1961, pp. 192-3).

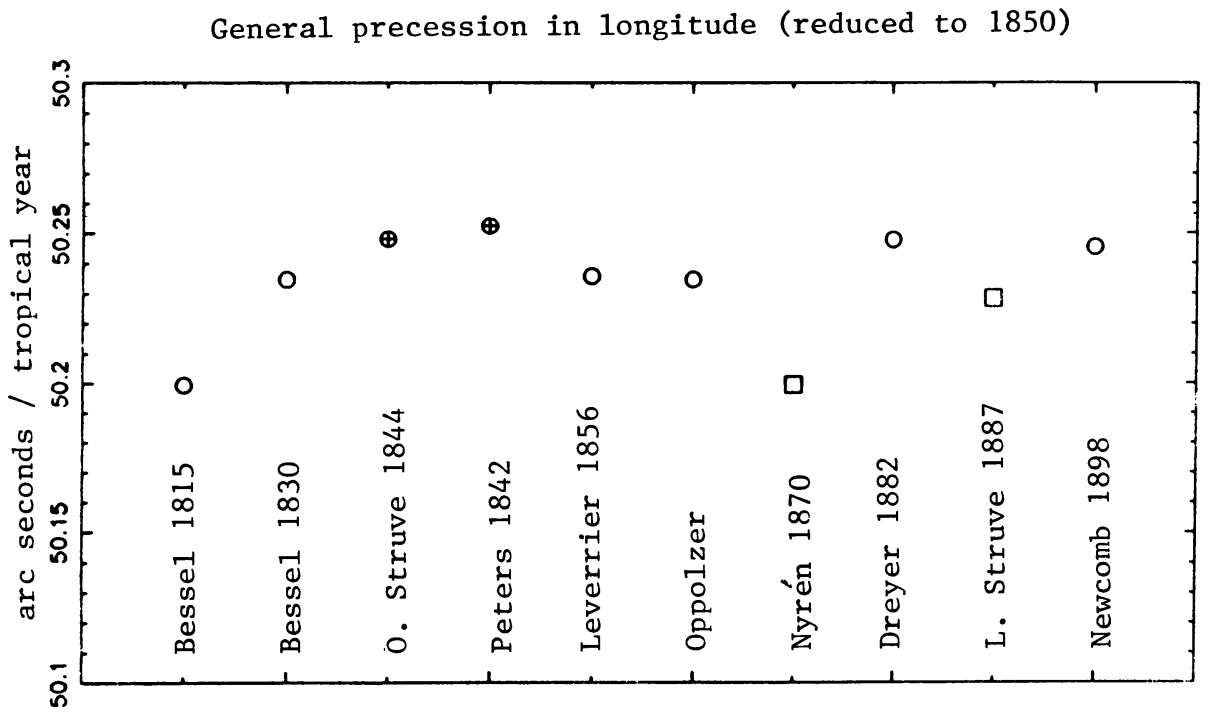

Fig. 3 - Various values of the general precession in longitude, reduced to 1850 (from Newcomb 1898, p. 10). Circles with crosses represent values based in part on Dorpat data. Squares represent values based in part on Pulkovo data. The value for 1850 based on modern theory is 50.25656 arcsec per tropical year (Lieske et al. 1977 , p. 14), and is indicated by the horizontal line.

Derived values for nutation are in close agreement with each other and overlap the modern accepted value (9'2025). In Fig. 4 we show data compiled by Harkness $(1891$, p. 25). While there is some scatter in the Greenwich values of $1838-1882$, the 
Dorpat and Pulkovo results are more self consistent. It is not surprising that the nutation values are on the whole correct. As Newcomb (1895, p. 129) points out:

The determination of this constant from observations is extremely satisfactory, owing to the completeness with which systematic errors may be eliminated. If, with a meridian instrument, regular observations are made through a draconitic period, on a uniform plan, upon stars equally distributed through the circle of Right Ascension, the observations being made daily through more than 12 hours of Right Ascension, all systematic errors in the determination of the nadir point and all having a diurnal or annual period may be completely eliminated from the constant in question.

Derived values of constant of nutation (1821-1885)

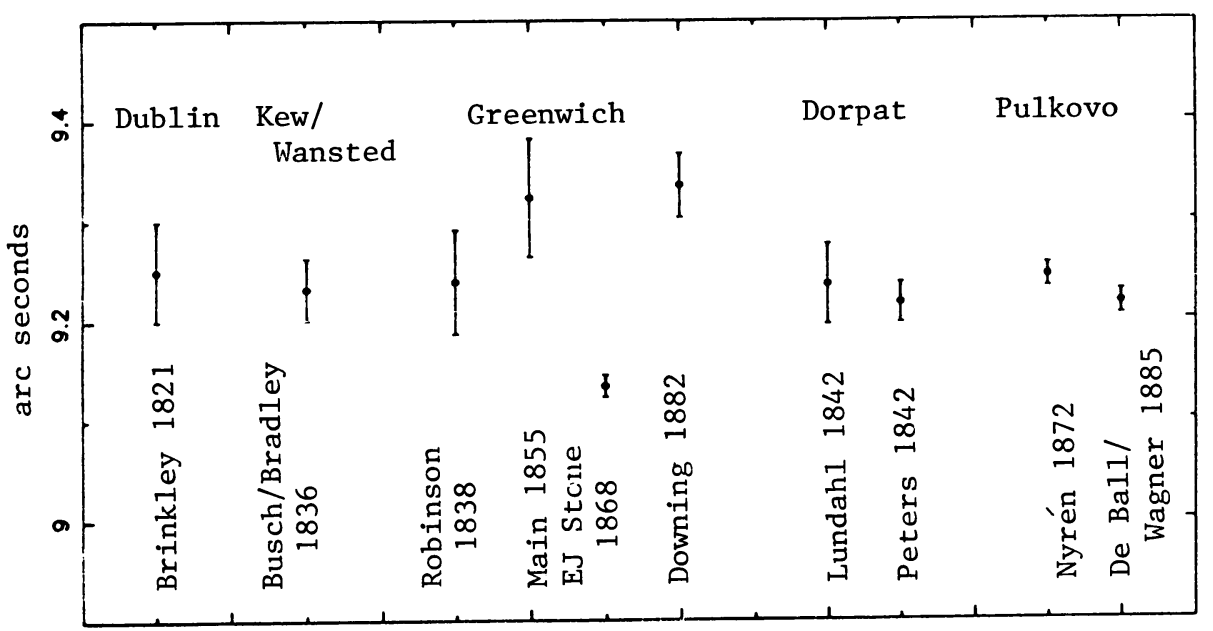

Fig. 4 - Derived values of nutation, given by Harkness (1891, p. 25) and grouped by observatory of origin. The modern value is 9.2025 arcsec (1989 Astronomical Almanac, p. K6), indicated by the horizontal line. Error bars are probable errors.

Newcomb $(1895$, p. 130) lists 27 determinations of the constant of nutation, including nine from Pulkovo data and 12 Greenwich values. The highest weight he assigns to observations of southern stars with the Washington transit circle (weight 6). Pulkovo values are generally weighted 3 and Greenwich weights average $21 / 3$. 
Newcomb's weighted result is $9^{\prime \prime} .210 \pm 0^{\prime \prime} .008$, the value accepted at the 1896 conference on astronomical constants (Procès-Verbaux 1896, p. D54).

Regarding aberration Newcomb $(1895$, p. 133) states: "This constant is itself the one of which the determination is most likely to be affected by systematic errors. In this respect it is at the opposite extreme from the constant of nutation."

In Fig. 5 we give some representative values of aberration, taken from Harkness (1891, pp. 25-6). Two preliminary values of W. Struve and his "final" value are given (W. Struve 1841, 1842, 1844). If we consider the results observatory by observatory, the Pulkovo results are clearly the most self consistent, and even have some of the smallest error bars.

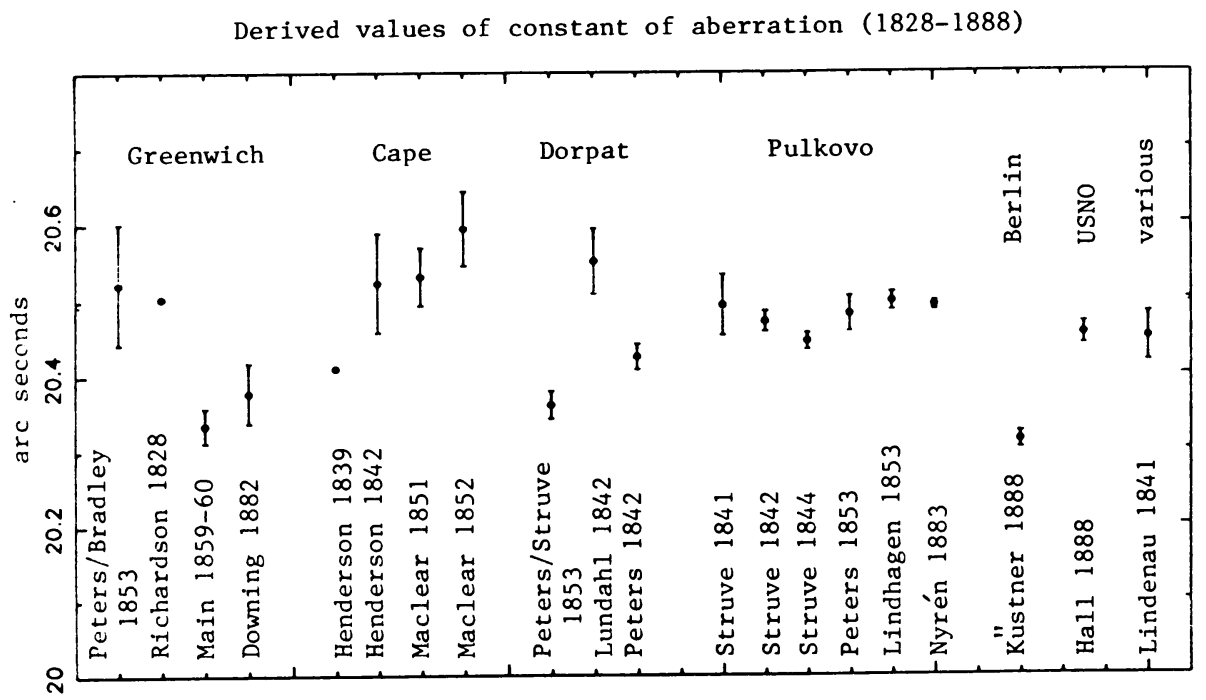

Fig. 5 - Derived values for constant of aberration, given by Harkness (1891, pp. 25-6) and grouped by observatory of origin. For two values no error bars were listed. The preliminary values of W. Struve (1841 and 1842) are shown, as well as his final value. The modern value is 20.49552 arcsec (1989 Astronomical Almanac, p. K6), indicated by the horizontal line. Error bars are probable errors.

From the self-consistency of the Pulkovo data Newcomb (1895, pp. 137-8) is justified in separating Pulkovo results from all others. For ten adjusted Pulkovo values Newcomb obtains 20 ".493 \pm 0 ".011. The other 24 values from other observatories give $20.463 \pm 0$ ".013. (The value adopted at the 1896 conference was 20.47 (Procè-Verbaux 1896 , p. D54). The modern value is 20.49552 .) 
Later in Newcomb's 1895 treatise (pp. 157, 166) he gives values of the solar parallax. From the Pulkovo constant of aberration he obtains 8".793 \pm 0 0.0046 . (The modern value is 8 ".794148.) There are nine values that Newcomb considers. He assigns a weight of 40 to the solar parallax value based on Pulkovo data. For the others he makes "liberal allowance for the more or less probable sources of systematic error". The other weights range from 1 to 10 , so the Pulkovo result is weighted 4 to 40 times higher than any of the other solar parallax values.

In Newcomb's estimation a century ago, or in our estimation with a century of hindsight, Pulkovo values of the 19th century for fundamental constants warranted very high regard. The best example to consider from an historical point of view is that of aberration, because of the possible sources of error, and it is this example that highlights the quality of positional work done at Pulkovo.

For a compilation of values of fundamental constants from the first half of the 20th century, see Böhme and Fricke (1963).

\section{Conclusions}

An observatory becomes famous partly as a result of how grandiose it is (i.e. big buildings, big telescopes). It draws the attention of the scientific world as a result of the reputation of its scientists and the quality of its work. If obvious discoveries occur, everyone takes note. If its work is of a systematic nature, such as the production of accurate star catalogues, the scientists take note if the results can be proven to have minimum systematic and random errors. All these conditions were met in the case of Pulkovo Observatory.

Pulkovo served as a reference point, a level to aspire to, for astronomers elsewhere. The Harvard 15-inch, which came on line in 1846, was known as the Pulkovo twin. Clearly, they wanted something as good as the best available, and Pulkovo's 15-inch was the standard of its era. Charles Piazzi Smyth, who visited Pulkovo in 1859, described another observatory on another trip of his as "like Pulkova perfectionised" (Brück and Brück 1988, p. 199). Pulkovo established a tradition of exactitude based on "Struve's method" and produced such fine results that B. A. Gould called it the "astronomical capital of the world." When Simon Newcomb analyzed determinations of astronomical constants, he weighted Pulkovo's results on aberration (a constant whose derivation is susceptible to systematic errors) far higher than all the other results. The Astronomer Royal, George Biddell Airy, stated in 1847 that no modern astrometrist could consider himself sufficiently trained until he had learned the methods developed at Pulkovo, since "a single observation made at Pulkovo is at least as valuable as two made elsewhere" (quoted by Otto Struve 1951).

In his History of Physical Astronomy, Robert Grant (18[52], p. 505) writes: "In short, the Observatory of Pulkowa may be regarded as one of the most complete in 
existence, of those institutions that have been founded for promoting the advancement of astronomical science." Another opinion is given by Agnes Clerke (1904, p. 44), who writes: "The institution created by [Struve] was acknowledged to surpass all others of its kind in splendour, efficiency, and completeness." "

As we celebrate the 150 th birthday of Pulkovo Observatory let us keep "Struve's method" in mind and proceed to evaluate the state of the art of positional astronomy in the late 20th century and see what it will become by the beginning of the 21 st.

\section{References}

The Astronomical Almanac for the year 1989, Washington: U. S. Government Printing Office and London: Her Majesty's Stationery Office.

Batten, Alan H. 1988, Resolute and Undertaking Characters: the Lives of Wilhelm and Otto Struve, Dordrecht: D. Reidel.

Böhme, S. and Fricke, W. 1963, in The System of Astronomical Constants, J. Kovalevsky ed., Paris: Gauthier-Villars (IAU Symposium No. 21), 269-293.

Brück, H. A. and Brück, M. T. 1988, The Peripatetic Astronomer: The Life of Charles Piazzi Smyth, Bristol and Philadelphia: Adam Hilger.

Chapman, A. 1983, J. Hist. Astr. 14, 133-137.

Clerke, Agnes M. 1904, A Popular History of Astronomy during the Nineteenth Century, London: Adam and Charles Black, 4th ed.

de Sitter, W. 1938, Bull. Astron. Insts. Neth. 8, 213-231. (This paper was completed by D. Brouwer.)

Dreyer, J. L. E. 1882, Copernicus (Dublin) 2, 135-155.

Dreyer, J. L. E. 1918, M. N. R. A. S. 78, 343-349.

Explanatory Supplement to The Astronomical Ephemeris and The American Ephemeris and Nautical Almanac, London: Her Majesty's Stationery Office, 1961, in particular pp. 168-174, 180-193.

Gliese, W. 1969, Catalogue of Nearby Stars, Veröffentlichungen des Astron. RechenInst. Heidelberg, No. 22.

Grant, Robert 18[52], History of Physical Astronomy from the Earliest Ages to the Middle of the Nineteenth Century, London: Henry G. Bohn.

Hall, A. 1888, Astron. J. 8, 1-13.

Harkness, W. 1891, "The solar parallax and its related constants, including the figure and density of the Earth," Washington Observations for 1885, Appendix III. 
Hughes, D. 1984, Nature 307, 15-16.

Krisciunas, Kevin 1988, Astronomical Centers of the World, Cambridge: Cambridge Univ. Press.

Lieske, J. H. 1985, Celestial Mechanics 37, 209-238.

Lieske, J. H., Lederle, T., Fricke, W., and Morando, B. 1977, Astron. Astrophys. 58, 1-16.

Newcomb, Simon 1895, The Elements of the Four Inner Planets and the Fundamental Constants of Astronomy, Washington: Government Printing Office.

Newcomb, Simon 1898, "A new determination of the precessional constant with the resulting precessional motions," Astronomical Papers prepared for the use of the American Ephemeris and Nautical Almanac 8, Washington: Government Printing Office.

Procès-Verbaux of the Conférence Internationale des Étoiles Fondamentales de 1896, Annales du Bureau des Longitudes 3, 18[96], pp. D1-D90.

Struve, Otto [Wilhelm] 1895, Zur Erinnerung an den Vater den Geschwistern dargebracht, Karlsruhe: G. Braun'schen Hofbuchdruckerei.

Struve, Otto 1951, Navigation 2, 302-305.

Struve, W. 1839, Astron. Nachrichten 16, No. 371, 163-166.

Struve, W. 1840, ibid. 17, No. 396, 177-180.

Struve, W. 1841, ibid. 18, No. 426, 289-294.

Struve, W. 1842, "Notice sur l'instrument des passages de Repsold, établi a L'Observatoire de Poulkova dans le premier vertical, sur les résultats que cet instrument a donnés pour l'evaluation de la constante de l'aberration, Bulletin scientifique publié par l'Académie imp. des Sciences de St.-Pétersbourg 10, No. 14, 15, 16.

Struve, W. 1844, "Sur le coefficient constant dans l'aberration des étoiles fixes déduit des observations que ont été exécutées à l'observatoire de Poulkova par l'instrument des passages de Repsold établi dans le premier vertical," Mém. de l'Acad. Imp. des Sci. de St.-Pétersbourg, Sci. Math. et Phys. 3, 229-285.

Struve, [F. G.] W. 1845, Description de L'Observatoire Astronomique central de Poulkova, St. Petersburg: Imprimerie de L'Académie Imperiale des Sciences.

Struve, [F. G.] W. 1852, Stellarum Fixarum imprimis Duplicium et multiplicium Positiones Mediae pro epocha 1830.0 deductae ex observationibus meridianis annis 1822 ad 1843 in specula Dorpatensi, St. Petersburg. 